Pacific Journal of Mathematics

A CLASS OF GENERALIZED FUNCTIONAL DIFFERENTIAL 


\title{
A CLASS OF GENERALIZED FUNCTIONAL DIFFERENTIAL EQUATIONS
}

\author{
MURIL ROBERTSON
}

In this paper, the equation $y^{\prime}=A y$ is solved, where $A$ is a self-mapping of a certain set of functions. Also, a continuous dependence theorem is proven, and $n$ th-order differential equations are considered.

1. Definitions. If $p$ is a real number and $I=\left\{I_{1}, I_{2}, \cdots\right\}$ is a collection of intervals so that $p \in I_{1}$ and $I_{n} \subseteq I_{n+1}$ for each positive integer $n$, then $I$ is said to be a nest of intervals about $p$. Let $I_{0}=$ $\{p\}$ and $\left[a_{n}, b_{n}\right]=I_{n}$ for each nonnegative integer $n$. Let $I^{*}$ denote the union of all the elements of $I$.

In general, $B$ denotes a Banach space; and if $D$ is a real number set, let $C[D, B]$ denote the set of continuous functions from $D$ into $B$. Whenever $D$ is an interval, $C[D, B]$ is considered a Banach space with supremum norm $|\cdot|$.

Let $C(I, B)$ denote the set of continuous functions whose domain is either $I_{0}, I^{*}$, or an element of $I$; and whose range is a subset of $B$.

Suppose $A$ is a mapping from $C(I, B)$ into $C(I, B)$ so that

(i) domain $f=$ domain $A f$, for all $f \in C(I, B)$,

(ii) $\left.(A f)\right|_{I_{k}}=A\left(\left.f\right|_{I_{k}}\right)$, for all $f \in C(I, B)$ and $I_{k} \leqq$ domain $f$, for positive $k$, [Note: $\left.f\right|_{I_{k}}$ is the restriction of $f$ to $I_{k}$.] and

(iii) there is a function $M$ from $I^{*}$ into the nonnegative reals that is Lebesgue integrable on any interval contained in $I$, so that $\|A f(x)-A g(x)\| \leqq M(x) \cdot|f-g|$, for all $f, g \in C\left[I_{i}, B\right]$ so that $\left.f\right|_{I_{i-1}}=$ $\left.g\right|_{I_{i-1}}$ and $x \in I_{i}$, for each positive integer $i$.

Then, $A$ is said to be an $I$-map with function $M$. Furthermore, if the phrase " $\left.f\right|_{I_{i-1}}=\left.g\right|_{I_{i-1}}$ " is removed from part (iii) of the previous definition, $A$ is said to be an $I$-map with strong function $M$.

\section{Main results.}

THEOREM A. Suppose $A$ is an I-map with function $M$; and $\max \left\{\int_{a_{i}}^{a_{i-1}} M, \int_{b_{i-1}}^{b_{i}} M\right\}<1$, for all positive integers $i$. Then if $q \in B$, there is a unique $y \in C\left[I^{*}, B\right]$ so that $y^{\prime}=A y$ and $y(p)=q$.

Proof. Let $\{(p, q)\}=y_{0}$. Then $y_{0}$ is the unique function in $C\left[I_{0}, B\right]$ so that $y_{0}(x)=q+\int_{p}^{x} A y_{0}$ for all $x \in I_{0}$. Now, suppose $n$ is a nonnegative integer so that $y_{n}$ has been defined in $C\left[I_{n}, B\right]$ to be the unique function so that $y_{n}(x)=q+\int_{p}^{x} A y_{n}$ for all $x \in I_{n}$. Then, $D=$ 
$\left\{f \in C\left[I_{n+1}, B\right] /\left.f\right|_{I_{n}}=y_{n}\right\}$ is a complete metric space. If $f \in D$, let $T f(x)=q+\int_{p}^{x} A f$, for all $x \in I_{n+1}$. Now if $x \in I_{n}$ and $f \in D$, then $T_{f}(x)=q+\int_{p}^{x} A f=q+\left.\int_{p}^{x}(A f)\right|_{I_{n}}=q+\int_{p}^{x} A\left(\left.f\right|_{I_{n}}\right)=q+\int_{p}^{x} A y_{n}=y_{n}(x)$. Thus $\left.(T f)\right|_{I_{n}}=y_{n}$, and thus $T f \in D$.

Suppose $f, g \in D$. Then,

$$
\begin{aligned}
|T f-T g| & =\max \left\{\|T f(x)-T g(x)\| / x \in I_{n+1}\right\} \\
& =\max \left\{\left\|\int_{p}^{x}(A f-A g)\right\|\right\} \\
& \leqq \max \left\{\left|\int_{p}^{x}\|A f(s)-A g(s)\| d s\right|\right\} .
\end{aligned}
$$

Note that $\left.f\right|_{I_{n}}=\left.g\right|_{I_{n}}$ and this implies that $A\left(\left.f\right|_{I_{n}}\right)=A\left(\left.g\right|_{I_{n}}\right)$. Thus, $\left.(A f)\right|_{I_{n}}=\left.(A g)\right|_{I_{n}}$; that is, $A f(s)=A g(s)$ for all $s$ in $I_{n}$. So

$$
\begin{aligned}
|T f-T g| \leqq \max \left\{\sup \left\{\int_{b_{n}}^{x}\|A f(s)-A g(s)\| d s / x \in\left[b_{n}, b_{n+1}\right]\right\},\right. \\
\left.\quad \sup \left\{\int_{x}^{a_{n}}\|A f(s)-A g(s)\| d s / x \in\left[a_{n+1}, a_{n}\right]\right\}\right\} \\
\leqq \max \left\{\sup \left\{\int_{b_{n}}^{x} M(s) \cdot|f-g| d s / x \in\left[b_{n}, b_{n+1}\right]\right\},\right. \\
\left.\quad \sup \left\{\int_{x}^{a_{n}} M(s) \cdot|f-g| d s / x \in\left[a_{n+1}, a_{n}\right]\right\}\right\} \\
\leqq \max \left\{\int_{a_{n+1}}^{a_{n}} M, \int_{b_{n}}^{b_{n+1}} M\right\} \cdot|f-g| .
\end{aligned}
$$

Hence $T$ is a contraction map from the complete metric space $D$ into $D$, and thus $T$ has a unique fixed point $y_{n+1}$. So $y_{n+1}$ is the unique function in $C\left[I_{n+1}, B\right]$ so that $y_{n+1}(x)=q+\int_{p}^{x} A y_{n+1}$ for all $x$ in $I_{n+1}$. So by induction $y_{k}$ is defined for each positive integer $k$. Define $y(x)=$ $y_{m}(x)$ whenever $x \in I_{m} \backslash I_{m-1}$. Then $y$ is the desired function.

The following corollary (See [6].) shows that Theorem A guarantees the existence of solutions to some functional differential equations. Suppose $g$ is a function from $I^{*}$ to $I^{*}$ so that $g\left(I_{n}\right) \subseteq I_{n}$ for each positive integer $n$. Such a function is said to be an $I$-function. Let $A_{k}=\left\{x \in\left[a_{k}, a_{k-1}\right] / g(x) \notin I_{k-1}\right\}$ and let $B_{k}=\left\{x \in\left[b_{k-1}, b_{k}\right] / g(x) \notin I_{k-1}\right\}$, for each positive integer $k$. Also, suppose $\|F(x, y)-F(x, z)\| \leqq M(x) \cdot\|y-z\|$ for all $x \in I^{*}, y, z \in B$; and $M$ is Lebesgue integrable on intervals.

Corollary. If $q \in B$, and $\max \left\{\int_{A_{k}} M, \int_{B_{k}} M\right\}<1$, for all $k$; then there is a unique $y \in C\left[I^{*}, B\right]$ so that $y(p)=q$ and $y^{\prime}(x)=F(x, y(g(x)))$ for all $x \in I^{*}$. 
Proof. Let $(A f)(x)=F(x, f(g(x)))$. Then $A$ is an $I$-map with function $T$, where

$$
T(x)=\left\{\begin{array}{ll}
M(x), & x \in A_{n} \cup B_{n} \\
0, & x \notin A_{n} \cup B_{n}
\end{array}, \quad \text { for } x \in I_{n} \backslash I_{n-1} .\right.
$$

The proof of the following is straightforward.

Proposition. Suppose $I$ is a nest of intervals about $p$, and each of $\alpha$ and $\beta$ is an I-function. Then

(i) Suppose $P$ is of bounded variation on each interval contained in $I^{*}$, and let $A f(x)=\int_{\alpha(x)}^{\beta(x)} d F \cdot f$, for $f \in C(I, B)$ and $x \in \operatorname{domain} f$. Then $A$ is an I-map with function $M$, where $M(x)$ is the variation of $F$ over $[\alpha(x), \beta(x)] \backslash I_{k-1}$ where $x \in I_{k} \backslash I_{k-1}$.

(ii) Suppose $K: I^{*} \times I^{*}$ to the scalars which is continuous, and $A f(x)=\int_{\alpha(x)}^{\beta(x)} K(x, t) f(t) d t$, for $f \in C(I, B)$ and $x \in$ domain $f$. Then $A$ is an I-map with function $M$, where $M(x)=\left|\int_{\left[\alpha(x), \beta(x) \backslash \backslash I_{k-1}\right.}\right| K(x, t)|d t|$ for $x \in I_{k} \backslash I_{k-1}$.

It is easy to show that the set of $I$-maps, for a fixed nest of intervals $I$, is a near-ring under composition and addition. Thus, there are many types of differential equations that may be solved by combining I-maps of the types given in the corollary and the proposition.

\section{Continuous dependence.}

THEOREM B. Suppose $A(z, \cdot)$ is an I-map with strong function $M_{b_{k}}$ for each $z$ in the topological space $K, q \in B$, and $M_{k}=\max \left\{\int_{a_{k}}^{a_{k-1}} M\right.$, $\left.\int_{b_{k-1}}^{b_{k}} M\right\}<1$, for all positive integers $k$. Let $y(z, \cdot)$ be the unique function, guaranteed by Theorem A, so that $y_{2}(z, \cdot)=A(z, y(z, \cdot))$ and $y(z, p)=q$. Then, there exists a sequence $\left\{L_{i}\right\}$ so that for $z, z_{0} \in K$, $\left|y(z, \cdot)-y\left(z_{0}, \cdot\right)\right|_{I_{i}} \leqq L_{i} \cdot\left|A\left(z, y\left(z_{0}, \cdot\right)\right)-A\left(z_{0}, y\left(z_{0}, \cdot\right)\right)\right|_{I_{i}}$, for each $i$. [In the previous inequality the norm is the supremum norm over $I_{i}$.]

Indication of proof. Define $\left\{L_{i}\right\}$ as follows: Let $L_{1}=\max \left(p-a_{1}\right.$, $\left.b_{1}-p\right) /\left(1-M_{1}\right)$. For $i \geqq 1$, let $L_{i+1}=\left\{L_{i}+\max \left(a_{i}-a_{i+1}, b_{i+1}-b_{i}\right)\right\} /$ $\left(1-M_{i+1}\right)$.

ExAmple. Let $g$ be an $I$-function and let $N>0$. Then let $K$ be the metric space of all $I$-functions that are pointwise never more that $N$ from $g$. Define $A(h, y)=y\left(\left.h\right|_{\text {dom } y}\right)$ and $d\left(h_{1}, h_{2}\right)=\sup \left\{\mid h_{1}(x)-\right.$ $\left.h_{2}(x) \mid / x \in I^{*}\right) ; d$ is the metric. 


\section{Nth order equations.}

THeOREM C. Suppose $A$ is an I-map with function $M, n$ is a positive integer, and $q_{0}, q_{1}, \cdots, q_{n-1} \in B$. Let

$$
\begin{gathered}
N_{k}=\max \left\{\int_{a_{k}}^{a_{k-1}} \int_{s_{1}}^{a_{k-1}} \cdots \int_{s_{n-1}}^{a_{k-1}} M\left(s_{n}\right) d s_{n} \cdots d s_{1},\right. \\
\left.\int_{b_{k-1}}^{b_{k}} \int_{b_{k-1}}^{s_{1}} \cdots \int_{b_{k-1}}^{s_{n-1}} M\left(s_{n}\right) d s_{n} \cdots d s_{1}\right\} .
\end{gathered}
$$

Then, if $N_{k}<1$, for all positive integers $k$, there is a unique $y \in$ $C\left[I^{*}, B\right]$ so that $y^{(n)}=A$ and $y(p)=q_{o}, \cdots, y^{(n-1)}(p)=q_{n-1}$.

Indication of proof. Use induction, Theorem A, and the following lemma.

Lemma. Suppose $H$ is an I-map with function $S$, and $q \in B$, then define $K f(x)=q+\int_{p}^{x} H f$, for all $f \in C(I, B)$ and $x \in \operatorname{domain} f$. Then $K$ is an I-map with function $T$, where $T(x)=\int_{x}^{a_{k}-1} S$, whenever $x \in$ $\left(a_{k}, a_{k-1}\right]$; and $T(x)=\int_{b_{k-1}}^{x} S$, whenever $x \in\left[b_{k-1}, b_{k}\right)$.

The proof of Theorem D is straightforward and Theorem $\mathrm{E}$ is a special case of Theorem D. Both of these theorems are imitations of standard theorems of ordinary differential equations.

TheOREM D. (A generalized system of equations theorem.) Suppose $B_{i}$ is a Banach space with norm $\|\cdot\|_{i}$, for each positive integer $i$ between 1 and $n$. Let $B^{\prime}=\left\{\left(x_{1}, x_{2}, \cdots, x_{n}\right) / x_{i} \in B_{i}\right\}$. Also, let $\|\left(x_{1}, \cdots\right.$, $\left.x_{n}\right) \|=\max \left\{\left\|x_{i}\right\|_{i} / 1 \leqq i \leqq n\right\}$, for all elements of $B^{\prime}$. [Then $B^{\prime}$ is a Banach space.] Furthermore, suppose $H_{i}: C\left(I, B^{\prime}\right)$ to $C\left(I, B_{i}\right)$ for $1 \leqq$ $i \leqq n$ so that

(1) if $f \in C\left(I, B^{\prime}\right)$, domain $f=$ domain $H_{i} f$,

(2) if $f \in C\left(I, B^{\prime}\right)$, and $I_{k} \leqq$ domain $f, k>0$, then $\left.\left(H_{i} f\right)\right|_{I_{k}}=$ $H_{i}\left(\left.f\right|_{I_{k}}\right)$, and

(3) there is $M_{i}: I^{*}$ to the reals which is Lebesgue integrable on intervals so that if $f, g \in C\left[I_{k}, B^{\prime}\right],\left.f\right|_{I_{k-1}}=g \mid I_{k-1}$, and $x \in I_{k}$, then $\left\|H_{i} f(x)-H_{i} g(x)\right\| \leqq M_{i}(x) \cdot|f-g|$. Now, define $A: C\left(I, B^{\prime}\right)$ to $C\left(I, B^{\prime}\right)$ so that $A f=\left(H_{1} f, H_{2} f, \cdots, H_{n} f\right)$, for all $f \in C\left(I, B^{\prime}\right)$.

Then $A$ is an $I$-map with function $\max \left\{M_{i} / 1 \leqq i \leqq n\right\}$.

Theorem E. Suppose $B^{\prime}$ is as in Theorem D, with $B=B_{i}$, for all i. Also, suppose $H=H_{n}$ and $M=M_{n}$, where $H_{n}$ and $M_{n}$ are as in Theorem D. Suppose $q_{0}, \cdots, q_{n-1} \in B$ and 


$$
\max \left\{\int_{a_{k}}^{a_{k-1}} \max \{1, M\}, \int_{b_{k-1}}^{b_{k}} \max \{1, M\}\right\}<1 \text {, for all } k>0 \text {. }
$$

Then, there is a unique $y \in C\left[I^{*}, B\right]$ so that

$$
y^{(n)}=H\left(\left(y, y^{(1)}, \cdots, y^{(n-1)}\right)\right) \text { and } y^{(i)}=q_{i} \text {, for } 0 \leqq i \leqq n-\iota .
$$

ExAMPLE. Suppose each $g_{i}$ is an $I$-function, then for appropriate functions $F_{i}$, Theorem $\mathrm{E}$ guarantees the existence of a solution to

$$
y^{(n)}(x)=\sum_{k=1}^{n} F_{k}\left(x, y^{(n-k)}\left(g_{k}(x)\right)\right) \text {, for all } x \in I^{*} \text {. }
$$

\section{REFERENCES}

1. David R. Anderson, An existence theorem for a solution of $f^{\prime}(x)=F(x, f(g(x)))$, SIAM Review, 8 (1966), 359-362.

2. Gregory M. Dunkel, On nested functional differential equations, SIAM J. of Appl. Math., 18 (1970), 514-525.

3. W. B. Fite, Properties of the solutions of certain functional differential equations, Trans. Amer. Math. Soc., 22 (1921), 311-319.

4. Jack Hale, Functional Differential Equations, Springer-Verlag, New York, 1971.

5. Robert J. Oberg, On the local existence of solutions of certain functional differential equations, Proc. Amer. Math. Soc., 20 (1969), 295-302.

6. Muril Robertson, The equation $y^{\prime}(t)=F(t, y(g(t)))$, Pacific J. Math., 43 (1972), 483491.

7. Y. T. Siu, On the solution of the equation $f^{\prime}(x)=\lambda f(g(x))$, Math. Z., 90 (1965), 391392.

Received May 10, 1972. This research was supported in part by a National Aeronautics and Space Administration Traineeship, and is part of the author's $\mathrm{Ph}$. D. thesis, which was directed by J. W. Neuberger, Emory University.

AUbURN UnIVERSITY 



\section{PACIFIC JOURNAL OF MATHEMATICS}

\section{EDITORS}

D. Gilbarg AND J. MILGRAM

Stanford University

Stanford, California 94305

\section{R. A. Beaumont}

University of Washington

Seattle, Washington 98105

\section{J. DUGUNDJI*}

Department of Mathematics University of Southern California Los Angeles, California 90007

RICHARD ARENS

University of California Los Angeles, California 90024

\section{ASSOCIATE EDITORS}
E. F. BECKENBACH
B. H. NEUMANN
F. WOLF
K. YoshidA

\section{SUPPORTING INSTITUTIONS}

\author{
UNIVERSITY OF BRITISH COLUMBIA \\ CALIFORNIA INSTITUTE OF TECHNOLOGY \\ UNIVERSITY OF CALIFORNIA \\ MONTANA STATE UNIVERSITY \\ UNIVERSITY OF NEVADA \\ NEW MEXICO STATE UNIVERSITY \\ OREGON STATE UNIVERSITY \\ UNIVERSITY OF OREGON \\ OSAKA UNIVERSITY
}

\author{
UNIVERSITY OF SOUTHERN CALIFORNIA \\ STANFORD UNIVERSITY \\ UNIVERSITY OF TOKYO \\ UNIVERSITY OF UTAH \\ WASHINGTON STATE UNIVERSITY \\ UNIVERSITY OF WASHINGTON \\ AMERICAN MATHEMATICAL SOCIETY \\ NAVAL WEAPONS CENTER
}

The Supporting Institutions listed above contribute to the cost of publication of this Journal, but they are not owners or publishers and have no responsibility for its content or policies.

Mathematical papers intended for publication in the Pacific Journal of Mathematics should be in typed form or offset-reproduced, (not dittoed), double spaced with large margins. Underline Greek letters in red, German in green, and script in blue. The first paragraph or two must be capable of being used separately as a synopsis of the entire paper. Items of the bibliography should not be cited there unless absolutely necessary, in which case they must be identified by author and Journal, rather than by item number. Manuscripts, in duplicate if possible, may be sent to any one of the four editors. Please classify according to the scheme of Math. Rev. Index to Vol. 39. All other communications to the editors should be addressed to the managing editor, Richard Arens, University of California, Los Angeles, California, 90024.

50 reprints are provided free for each article; additional copies may be obtained at cost in multiples of 50 .

The Pacific Journal of Mathematics is issued monthly as of January 1966. Regular subscription rate: $\$ 48.00$ a year (6 Vols., 12 issues). Special rate: $\$ 24.00$ a year to individual members of supporting institutions.

Subscriptions, orders for back numbers, and changes of address should be sent to Pacific Journal of Mathematics, 103 Highland Boulevard, Berkeley, California, 94708.

PUBLISHED BY PACIFIC JOURNAL OF MATHEMATICS, A NON-PROFIT CORPORATION

Printed at Kokusai Bunken Insatsusha (International Academic Printing Co., Ltd.), 270, 3-chome Totsuka-cho, Shinjuku-ku, Tokyo 160, Japan.

* C. DePrima will replace J. Dugundji until August 1974.

Copyright (C) 1973 by

Pacific Journal of Mathematics

All Rights Reserved 


\section{Pacific Journal of Mathematics}

\section{Vol. 47, No. $2 \quad$ February, 1973}

David Parham Bellamy, Composants of Hausdorff indecomposable continua; a mapping approach ........................ 303

Colin Bennett, A Hausdorff-Young theorem for rearrangement-invariant spaces ...........................................

Roger Daniel Bleier and Paul F. Conrad, The lattice of closed ideals and $a^{*}$-extensions of an abelian l-group ...

Ronald Elroy Bruck, Jr., Nonexpansive projections on subsets of Banach

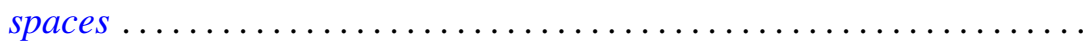

Robert C. Busby, Centralizers of twisted group algebras ............. 357

M. J. Canfell, Dimension theory in zero-set spaces ................ 393

John Dauns, One sided prime ideals ........................ 401

Charles F. Dunkl, Structure hypergroups for measure algebras . . . . . . . . . 413

Ronald Francis Gariepy, Geometric properties of Sobolev mappings ...... 427

Ralph Allen Gellar and Lavon Barry Page, A new look at some familiar spaces of intertwining operators ...........................

Dennis Michael Girard, The behavior of the norm of an automorphism of the

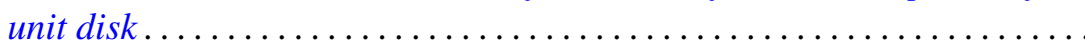

George Rudolph Gordh, Jr., Terminal subcontinua of hereditarily

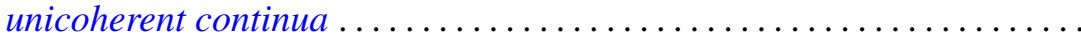

Joe Alston Guthrie, Mapping spaces and cs-networks. .

Neil Hindman, The product of $F$-spaces with $P$-spaces . 473

M. A. Labbé and John Wolfe, Isomorphic classes of the spaces $C_{\sigma}(S)$

Ernest A. Michael, On k-spaces, $k_{R}$-spaces and $k(X) \ldots$

Donald Steven Passman, Primitive group rings .

C. P. L. Rhodes, A note on primary decompositions of a pseudovaluation ...

Muril Lynn Robertson, A class of generalized functional differential equations

Ruth Silverman, Decomposition of plane convex sets. $I$.

Ernest Lester Stitzinger, On saturated formations of solvable Lie algebras................................

B. Andreas Troesch, Sloshing frequencies in a half-space by Kelvin inversion ...

L. E. Ward, Fixed point sets .

Michael John Westwater, Hilbert transforms, and a problem in scattering

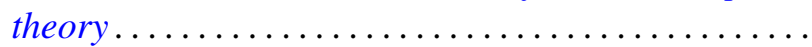

Misha Zafran, On the spectra of multipliers... 